\title{
Escola, conflitualidade e violência
}

\author{
Dirce Mendes da Fonseca' \\ Filipe Ferreira Marques ${ }^{2}$ \\ Philippe Vitoriano ${ }^{3}$ \\ Emily Mendes Xavier ${ }^{4}$
}

\section{Resumo}

O objeto desta pesquisa foi o estudo a respeito da violência e das relações sociais na escola, com vista a identificar as manifestações de violência na forma real ou simbólica, direta ou indireta. $\mathrm{O}$ foco principal foi a análise da realidade de uma escola pública do Distrito Federal. A metodologia utilizada com base em referenciais qualitativos utilizou-se de dados e observações colhidos por meio de entrevistas e de observação direta no cotidiano da escola. Os resultados obtidos indicam que a violência perpassa e está presente nas relações sociais e educacionais da escola, o que foi revelado por professores, por alunos e por funcionários.

Palavras-chave: Escola. Relações sociais. Violência.

\section{Introdução}

Este artigo é resultado da pesquisa a respeito do estudo do fenômeno ligado à conflitualidade, relações sociais e violência na escola. $\mathrm{O}$ tema reveste-se da maior importância no âmbito da sociedade, das políticas públicas e, especialmente, no campo específico da tipologia da violência e dos aspectos relacionados a ela. A escola, como local importante de socialização, de formação de atitudes, de valores e de construção de cidadania, constitui-se lugar de excelência para se estudar o fenômeno da violência, o qual está, ao mesmo tempo, refletindo a sociedade e provocando mudanças nas relações sociais e interpessoais. Há que se considerar que

1 Doutora em Sociologia, professora do curso de Mestrado em Direito do UniCEUB. mendesdirce@yahoo.com.br.

2 Participante do PIC Junior/FAP/DF 2009. filipek15@gmail.com.

3 Participante do PIC Junior/ FAP/DF 2009. philipevitoriano@gmail.com.

4 Participante do PIC Junior/FAP/DF 2009. emiilyxavier@gmail.com. 
outros espaços sociais constituem lócus de socialização e de formação de atitudes, tais como a família e grupos sociais. Foram objetivos deste estudo: identificar os discursos referentes à conflitualidade e à violência na fala dos entrevistados e identificar as relações sociais e as formas de violência em sua manifestação concreta.

Um ponto importante no estudo da violência é percebê-la não por si só, isolada num contexto social e familiar, mas compreendê-la a partir da categoria de violência relacional e da omissão das instâncias de proteção: família, Estado e sociedade.

A metodologia utilizada teve como ponto de partida a observação dos fenômenos, objeto desta pesquisa e como eles se manifestam nas relações sociais na comunidade escolar. A partir da observação, foram realizadas entrevistas semiestruturadas com alunos, professores, diretores e funcionários técnico-administrativos e auxiliares da escola.

A pesquisa foi desenvolvida em dois focos avaliativos. O primeiro esteve voltado para apreender, na visão dos jovens, o fenômeno da violência, como eles a percebem e como eles são, ao mesmo tempo, vítimas e sujeitos. O segundo foco foi centrado no estudo de uma realidade específica (escola pública do Distrito Federal), com vistas a identificar o fenômeno da violência e o perfil dos jovens que dela são sujeitos dentro da escola e nas relações sociais.

\section{Contextualização da conflitualidade e da violência}

A conflitualidade manifesta nas relações sociais da escola expressa o conflito de valores e de cultura de determinada sociedade. A escola não se encontra isolada do contexto social mais amplo. A violência e suas manifestações sempre estiveram presentes nas relações sociais, apresentando caráter histórico e cultural, tendo em vista que cada sociedade produz e reproduz a violência em diversos níveis. No entanto, é preciso compreender que não existe um conceito de violência, mas vários conceitos e, da mesma forma, vários tipos de violências. 
Bottomore (1988, p. 1.291) define violência da seguinte forma:

Por violência entende-se a intervenção física de um indivíduo ou grupo contra outro grupo (ou também contra si mesmo). Para que haja violência é preciso que a intervenção física seja voluntária [...]. Intervenção física, na qual a violência consiste tem por finalidade destruir, ofender e coagir [...]. A violência pode ser direta ou indireta. É direta quando atinge de maneira imediata o corpo de quem sofre. É indireta quando opera através de uma alteração do ambiente físico no qual a vítima se encontra [...] ou através da destruição, da manifestação ou da subtração dos recursos materiais. Em ambos os casos, o resultado é o mesmo: uma modificação prejudicial do estado físico do indivíduo ou grupo que é alvo da ação violenta.

Como se pode compreender, o conceito de violência é muito amplo, comportando diversas conotações, além de estar sujeito a mudanças, uma vez que os valores implícitos nesses atos vêm se modificando dialeticamente a partir das modificações sociais e culturais. Para melhor compreender o fenômeno da violência, Abravomovay (2003) aborda uma visão que vai além da multiplicidade de formas assumidas por ela, caracterizando que existem diferenças entre períodos históricos e culturas no que se refere à compreensão acerca do tema. Nesse sentido, pode-se inferir que a violência é um conceito relativo, histórico e mutável.

A violência não se restringe ou se baseia em fatos concretos como em crimes e delitos. "A violência é ressignificada, segundo tempos, lugares, relações e percepções e não se dá somente em atos e práticas materiais” (ABRAMOVAY, 2003, p. 47). Dessa forma, pode-se dizer que a violência se manifesta de forma direta e indireta, de forma real ou simbólica e pode ser identificada em vários lugares sociais, entre indivíduos, comunidade e sociedade.

A violência vem se destacando e se aprofundando e tem sido cada vez mais frequente entre os jovens e dentro das escolas, lugar que, paradoxalmente, é de formação e de construção de cidadania e de valores. Também se tem como exemplo do crescimento da violência as informações dos noticiários veiculados pela mídia impressa ou falada. Para Abramovay e Rua (2002), a escola não mais representa lugar seguro, de integração social, de socialização; não é mais um espaço resguardado; ao contrário, tornou-se cenário de ocorrências violentas. 
Pode-se considerar que os fatores que influenciam o aumento da violência estão associados a causas estruturais sociais e a fatores culturais. No entanto, não se pode esquecer que os fatores interpessoais desencadeiam também processos violentos.

É interessante destacar a multidimensionalidade da violência, imersa em vários fatores: a violência e as relações conflituosas presentes na relação aluno/professor e a violência estrutural e social.

Para Marília Sposito (2001), a violência nas escolas é um fenômeno que no Brasil teve início nos anos 80, com as ações contra o patrimônio escolar, tais como: depredações, furtos e outras manifestações.

Sabe-se que atitudes agressivas existem em escolas públicas e privadas, em bairros do centro e da periferia, em escolas de elite e até naquelas que atendem às classes populares. Isso acontece em razão de a escola refletir a sociedade da qual faz parte e absorver as complexidades e contradições advindas dela.

Sposito (2001) chama a atenção em sua pesquisa para o fato de a violência estar se focalizando nas escolas e não em outros sistemas como, por exemplo, o da saúde.

Retomando o levantamento realizado por Sposito (2001), é possível considerar que os anos 1990 mostram mudanças na forma de violência observada nas escolas públicas, não sendo somente atos de vandalismo que persistiam, mas a prática de agressões pessoais e morais.

É possível que não seja apenas a violência física que se manifeste no interior da escola, mas também a violência simbólica, mostrada em ações diretas e indiretas.

No que tange ao combate à violência nas escolas, há um consenso de que a paz deve ser restabelecida, restaurada; não é possível aprender e ensinar onde todos estão paralisados pelo medo, seja esse medo real ou imaginário. A violência escolar faz vítimas, principalmente entre os próprios alunos, nos conflitos que travam entre 
si e entre grupos. Assim, para que as relações sociais nas escolas sejam pedagógicas e educativas, torna-se necessário que tanto os alunos como toda a comunidade estabeleçam relações geradoras de atitudes e de valores que fortaleçam a convivência social colaborativa. Assim, a escola deve reforçar as relações pedagógicas de formação integral, para que os alunos não sofram nenhum tipo de preconceito e de discriminação.

\section{Caracterização institucional}

A pesquisa foi realizada em uma escola da rede pública do DF, situada na Asa Norte do Plano Piloto, em Brasília. O colégio contava, em 2009, com aproximadamente 6.809 alunos matriculados nos turnos matutino e noturno, divididos em sete turmas de $1^{\circ}$ ano, sete turmas de $2^{\circ}$ ano e cinco turmas de $3^{\circ}$ ano do ensino médio.

O corpo docente era constituído por 239 (duzentos e trinta e nove) professores, nas diferentes áreas do conhecimento, responsáveis pelo ensino e 3 (três) atividades pedagógicas. ${ }^{5}$

\subsection{Perfil dos alunos do turno matutino}

Para compreender as relações sociais na escola e os aspectos ligados à violência, foi traçado o perfil dos alunos. E é a partir deste perfil que se pode entender melhor as dinâmicas e as relações sociais na escola.

Quanto às porcentagens apresentadas a seguir, as que não completam 100\% da população investigada são em função das lacunas nas fichas de registro da escola.

- $40 \%$ masculino e $53 \%$ feminino;

- $72 \%$ entre 16 e 18 anos, $21 \%$ até 15 anos;

${ }_{5}$ Os dados desta pesquisa foram coletados a partir da Proposta Pedagógica da escola pesquisada. 
- $80 \%$ moram com os pais;

- $40 \%$ moram no Plano Piloto, $12 \%$ em Sobradinho, 7,6\% em condomínios, 4,7\% em Santa Maria e na Granja do Torto;
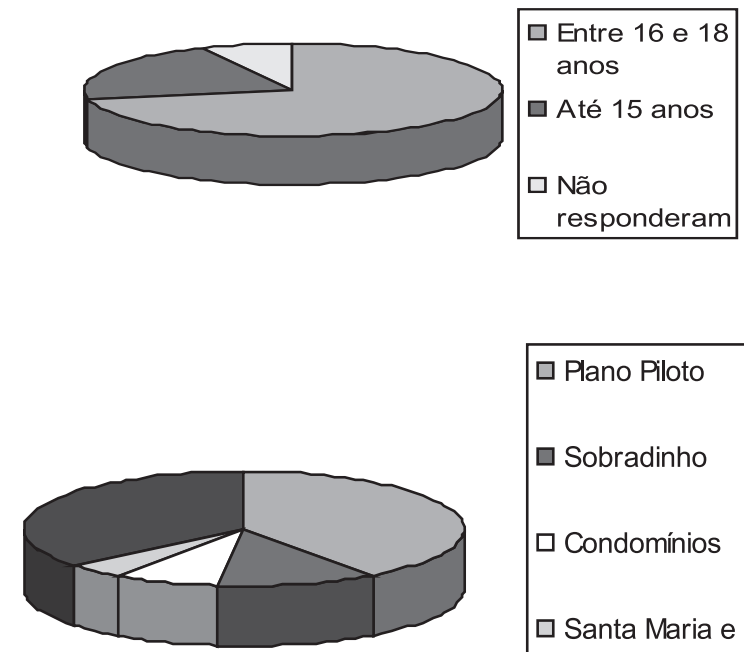

\begin{tabular}{|l|}
\hline$\square$ Plano Piloto \\
$\square$ Sobradinho \\
$\square$ Condomínios \\
$\square$ Santa Maria e \\
Granja do Torto \\
$\square$ Não Responderam \\
\hline
\end{tabular}

- $60,9 \%$ moram em casa própria e $29,8 \%$ em casa alugada;
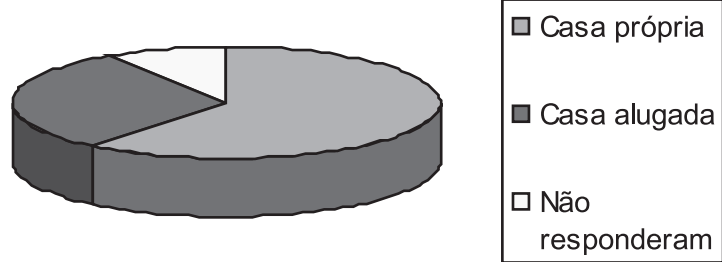

- 53\% são católicos, 30\% evangélicos e protestantes, 5\% espíritas;

- $41 \%$ têm renda de três a cinco salários mínimos, 6,5\% têm renda familiar de um a dois salários mínimos; 


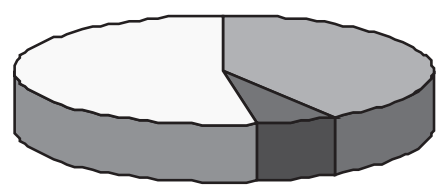

3 a 5 salários mínimos

- 1 a 2 salários mínimos

$\square$ Não responderam

- $51 \%$ nasceram no DF;

- $40 \%$ dos pais são separados e $80 \%$ moram com os pais;

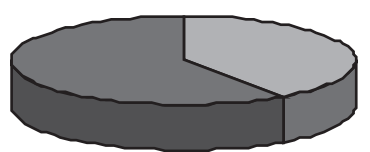

$\square$ Pais separados

口 Pais não separados

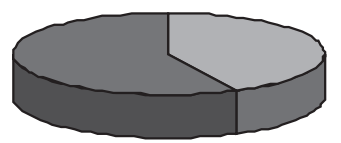

\begin{tabular}{|l}
\hline Moram com os \\
pais \\
$\square$ Não moram \\
com os pais
\end{tabular}

- $41,2 \%$ se consideram de cor parda, $32,4 \%$ de cor branca, $15,9 \%$ de cor negra, 6,5\% amarela e 3,1\% indígenas;

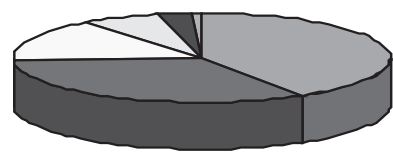

\begin{tabular}{|l|}
\hline$\square$ Pardos \\
$\square$ Brancos \\
$\square$ Negros \\
$\square$ Amarelos \\
$\square$ Indígenas \\
$\square$ Não responderam
\end{tabular}


- 20\% dos alunos são aprendizes ou estagiários com remuneração; apenas 5,9\% trabalham com carteira assinada e 19,4\% se consideram desempregados;

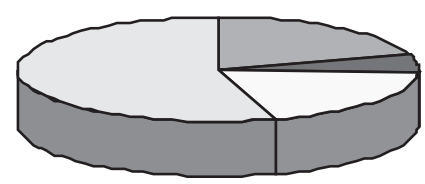

$\square$ Aprendizes ou estagiários

$\square$ Trabalham com carteira assinada

$\square$ Consideram-se desempregados

$\square$ Não responderam

- $48 \%$ utilizam transportes coletivos para chegar à escola, $26 \%$ vêm a pé e $19,4 \%$ vêm de carro;

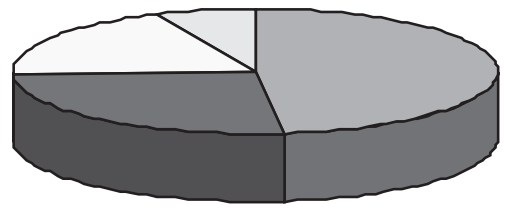

$\square$ Transportes coletivos

$\square$ A pé

$\square$ De carro

$\square$ Não responderam

- $60 \%$ dos alunos afirmam ter compromisso com os estudos e $71 \%$ têm boa disciplina na escola;

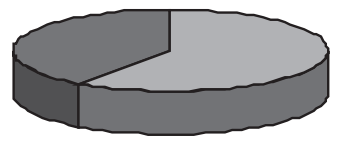

Compromisso
comos
estudos
Não tem
compromisso
com os
estudos




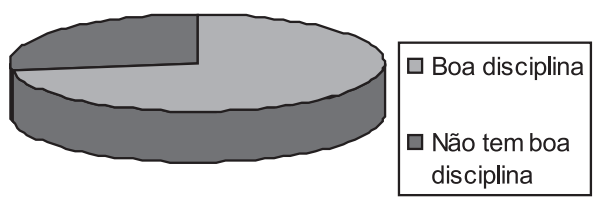

- Para $44,9 \%$ dos alunos a escola é boa, $43,7 \%$ a consideram regular e $11 \%$ consideram-na ruim;

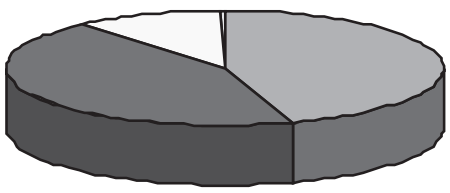

$\square$ Alunos que acham
a escola boa
$\square$ Alunos que acham
a escola regular
$\square$ Alunos que acham
a escola ruim
Alunos que não
responderam

- $\quad 90 \%$ afirmam a importância da escola na vida;

- $\quad 44 \%$ têm bom rendimento escolar, 50\% rendimento médio e $2,7 \%$ baixo rendimento;

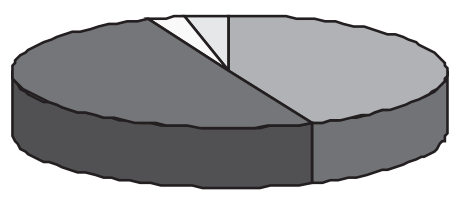

\begin{tabular}{|l|}
\hline Bom \\
$\square$ Médio \\
$\square$ Baixo \\
$\square$ Não responderam
\end{tabular}

- Apenas $11 \%$ dos pais têm curso superior, 7\% são pós-graduados, $30 \%$ têm ensino médio completo, $16 \%$ têm o ensino fundamental incompleto e $2,4 \%$ não sabem ler; 


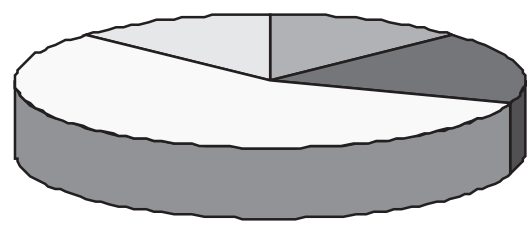

$\square$ Pais com curso
superior
$\square$ Pais pós-graduados
$\square$ Pais com Ensino Médio
$\square$ Pais com Ensino
Fundamental Incompleto
$\square$ Pais não sabem ler
$\square$ Não responderam

\subsection{Perfil dos alunos do curso noturno}

Os alunos do turno matutino têm uma realidade diferente dos alunos do turno noturno. Quanto às porcentagens apresentadas a seguir, as que não completam $100 \%$ da população investigada são em função das lacunas nas fichas de registro da escola.

- $32,4 \%$ Masculino e $67,3 \%$ Feminino;

- $46,9 \%$ têm mais de 25 anos, $40,2 \%$ têm entre 19 e 25 anos, $12,1 \%$ entre 16 e 18 anos;

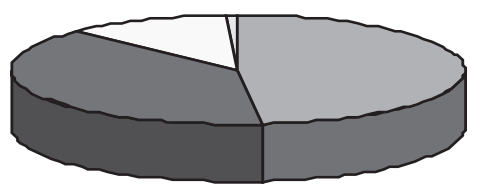

$\square$ Mais de 25 anos

$\square$ Entre 19 e 25 anos

$\square$ Entre 16 e 18 anos

$\square$ Não responderam

- 57,8 \% moram no Plano Piloto, 9,8\% no Varjão, $7 \%$ na Granja do Torto; 


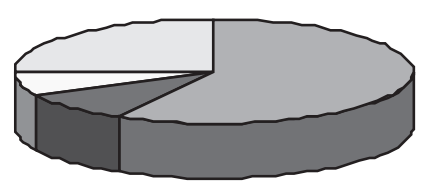

\begin{tabular}{|l|}
\hline$\square$ Plano Piloto \\
$\square$ Varjão \\
$\square$ Granja do Torto \\
$\square$ Não responderam
\end{tabular}

- $\quad$ Apenas $28 \%$ têm casa própria, $40 \%$ em casa alugada, $30 \%$ outra condição;

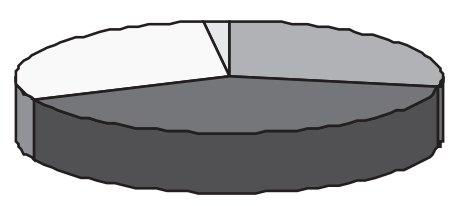

$\square$ Casa própria

$\square$ Alugada

$\square$ Outra condição

$\square$ Não responderam

- $\quad 24 \%$ moram com os pais, $65 \%$ alegaram outra condição;

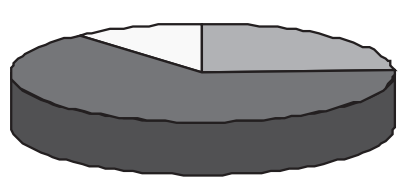

$\square$ Moram com os
pais
$\square$ Alegaram outra
condição
$\square$ Não
responderam

- $\quad 57,4 \%$ são católicos, 30\% evangélicos e protestantes;

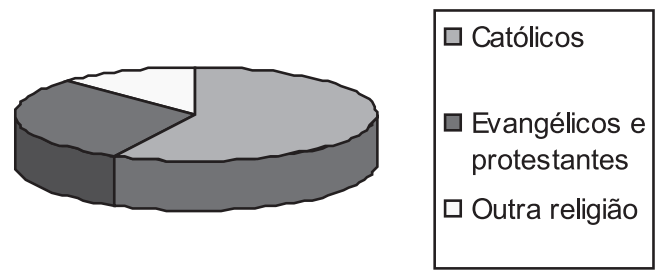


- 50,4\% têm renda familiar entre 1 e 2 salários mínimos, 30,9\% entre 3 e 5 e 12,9\% de 6 a 8 salários mínimos;

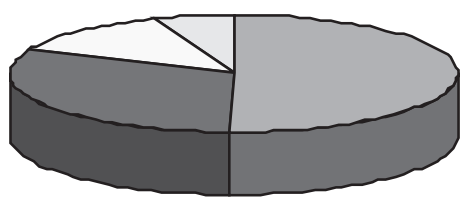

$\square 1$ e 2 salários mínimos

$\square 3$ a 5 salários mínimos

$\square 6$ a 8 salários mínimos

$\square$ Não responderam

- $19,1 \%$ nasceram no DF, $12 \%$ moram há mais de 10 anos no DF, e $26,2 \% \%$, há menos de 3 anos no DF;
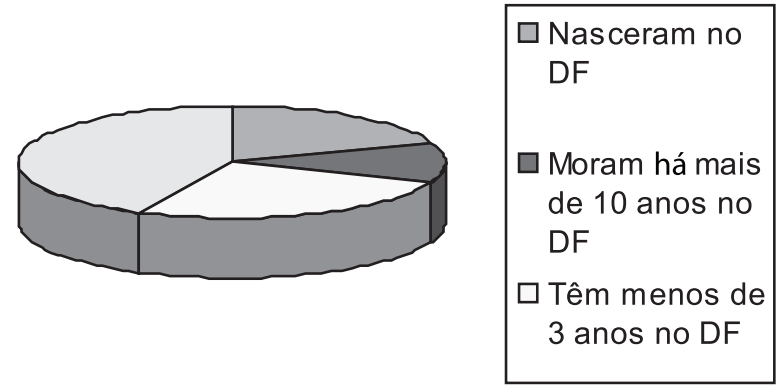

- $28 \%$ são órfãos de pai ou de mãe, $43 \%$ os pais moram juntos, $27,3 \%$ têm pais separados;

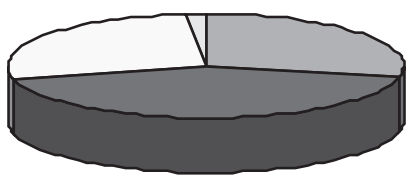

\begin{tabular}{|l|}
\hline Órfãos de pai ou \\
mãe \\
$\square$ Os pais moram \\
juntos \\
$\square$ Têm pais \\
separados \\
$\square$ Não responderam
\end{tabular}

- $55,1 \%$ se consideram de cor parda, $23,8 \%$ de cor branca, $14,8 \%$ negra, $4,3 \%$ amarela, $2 \%$ indígena; 


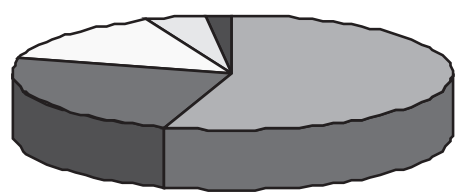

\begin{tabular}{|l|}
\hline Pardos \\
$\square$ Brancos \\
$\square$ Negros \\
$\square$ Amarelos \\
$\square$ Não responderam
\end{tabular}

- 7,4\% são estagiários, com remuneração, 53\% trabalham com carteira assinada, 30\% se consideram desempregados;

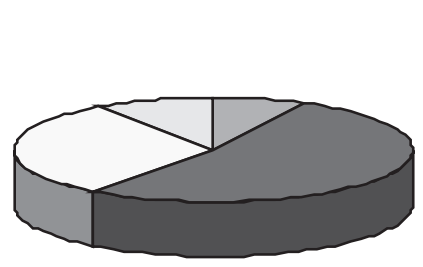

$$
\begin{gathered}
\square \text { Estagiários com } \\
\text { remuneração } \\
\square \text { Trabalham com } \\
\text { carteira assinada } \\
\square \text { Consideram-se } \\
\text { desempregados } \\
\square \text { Não responderam }
\end{gathered}
$$

- $55,9 \%$ utilizam coletivos para ir à escola, $32,8 \%$ vêm a pé, 5,9\% vêm de carona;

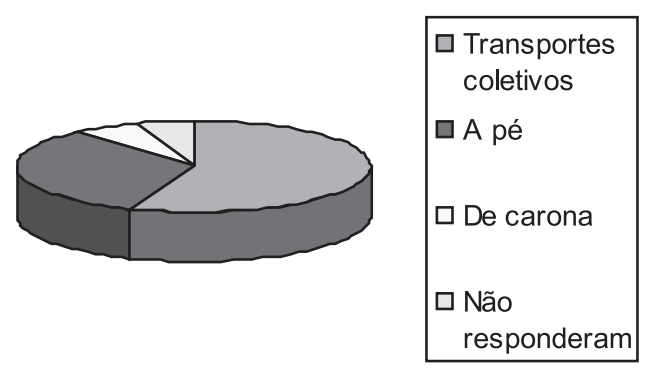

- $66,8 \%$ dos alunos afirmam ter compromisso com os estudos;

- $74,6 \%$ têm boa disciplina na escola; 


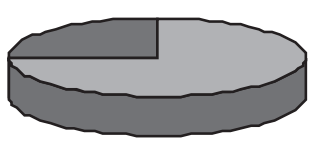

$$
\begin{array}{|c|}
\hline \text { Têm boa } \\
\text { disciplina } \\
\square \text { Não têm boa } \\
\text { disciplina }
\end{array}
$$

- Para 56\%, a escola é boa, 38,3\% consideram-na regular, 3,9\%, ruim;

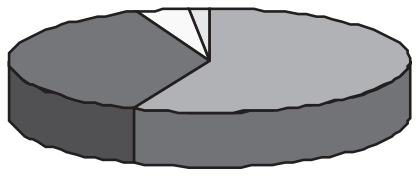

$\square$ Consideram a
escola boa
$\square$ Consideram a
escola regular
$\square$ Consideram a
escola ruim
Não
responderam

- $93 \%$ afirmam a importância da escola em sua vida;

- 34,8\% têm bom rendimento escolar, 59,9\% têm rendimento médio, $2 \%$, baixo rendimento;

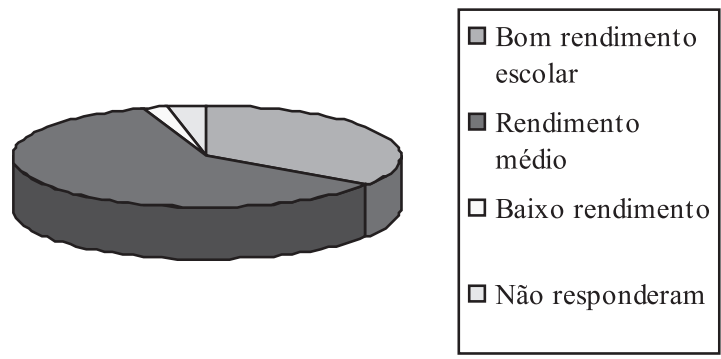

- $72,6 \%$ têm escolaridade abaixo do ensino médio.

Após a análise do perfil dos alunos do turno matutino e do noturno, foi possível observar algumas diferenças. Quando se trata dos alunos da manhã, são 
alunos mais novos, ainda dependentes dos pais e têm condição de vida pouco superior aos do noturno. A maioria não trabalha e se dedica apenas aos estudos.

Já os alunos do noturno apresentam situação bem diferente. A maioria tem emprego, o que denota outras responsabilidades impostas pela idade deles. Outro fato a destacar é que há uma maior proporção de pais dos alunos do ensino médio do turno diurno que concluíram o ensino superior do que os pais dos alunos do turno noturno, ressaltando-se que mais de três quartos dos pais têm escolaridade inferior ao ensino médio. Apesar dessas diferenças, no tocante à importância da escola e dos estudos, os alunos, pareceu-nos, terem encontrado um ponto em comum. Todos admitem que o estudo e a escola são importantes e são partes fundamentais em suas vidas, portanto, valorizam a escola.

\section{Relações sociais na escola}

A pesquisa procurou identificar as relações sociais na escola a partir da metodologia de identificação dessas relações por meio da observação com vistas a perceber nesse ambiente atitudes e comportamentos do cotidiano, mediante a fala dos alunos, gestos e ações que pudessem significar expressões de violências.

Para uma convivência social entre indivíduos e grupos, a comunicação é essencial, tendo em vista que a partir dos primeiros contatos podem se definir relações amigáveis ou não. O indivíduo é inserido em um grupo social por questões de afinidade sociais, religiosas, de trabalho, de interesse, entre outros motivos. Sabe-se ser mais fácil manter um bom desempenho no trabalho quando o indivíduo tem boa relação com os colegas. Para entender a dinâmica das relações sociais na escola, é interessante observar como os alunos constroem seus vínculos, como eles se comunicam e interagem.

A educação é também um processo social no qual os indivíduos participam enquanto realizam uma opção entre diferentes valores e objetivos a serem alcançados. A escola é um espaço público para a convivência fora da vida privada, íntima, familiar; e o indivíduo, ao capacitar-se para a convivência participativa na escola, 
participa de processos de aprendizagem que também o ensinam como participar do restante da vida social e vice versa. Nesse espaço social e educativo, ele se constrói como sujeito.

A escola, como esfera pública democrática, pode possibilitar a capacitação de pais, alunos e educadores na busca de soluções para os problemas da própria escola, do bairro, da cidade, do Estado, do país e da vida em sociedade. É a escola um lugar de formação, de aprendizagem e de interação da comunidade e dos vários segmentos nela estabelecidos.

Pautando-se no perfil dos alunos, a pesquisa procurou identificar as relações sociais estabelecidas na escola, considerando que elas refletem a forma de socialização entre as comunidades escolar e familiar. As relações sociais refletem as manifestações intraescolares e podem se apresentar como reflexo da violência social mais ampla, aquela presente nas famílias, nas comunidades e na sociedade.

Considera-se a escola um microespaço do espaço social mais amplo, onde os jovens são atores de processos sociais e interagem com eles algumas vezes como protagonistas e em outras como vitimas. É nesse contexto que as instituições, especialmente a escola, podem atuar significativamente de forma a promover processos de socialização capazes de desenvolver sujeitos para uma nova geração, os quais, por sua vez, poderão contribuir para a construção de novos valores e de uma nova cultura.

\subsection{Relação aluno/professor}

A convivência complexa e dinâmica entre alunos e professores marca o clima da escola que, por vezes, é cercado por conflitos entre eles, em outros momentos, por motivos supérfluos, mas pode chegar a desenvolver conflitos mais complexos. As causas que geram esses conflitos podem variar sob múltiplos aspectos.

De acordo com Abramovay (2003), crescem as manifestações de uma sociabilidade violenta, expostas de várias formas. Assim, a escola não representa mais um lugar seguro e de interação social. 
A pesquisa teve como foco identificar a visão dos alunos acerca das relações sociais no ambiente escolar. Por meio de entrevistas, os alunos responderam a seguinte questão: Em sua opinião, como é a relação entre aluno e professor?

As respostas centraram-se nas seguintes falas:

- $\quad$ Algumas boas, outras ruins, têm que melhorar muito.

- Mantemos o respeito e procuramos assumir um nível amigável, fazendo assim que as próprias aulas não se tornem monótonas. Porém, existem professores muito fechados, que usam do rigorismo e autoridade para obter respeito, o que, às vezes, é a pior maneira de se relacionar.

- Depende de cada professor e de cada aluno; tudo pode acontecer em sala de aula.

- Depende muito dos dois, é como um amigo depender das afinidades, conversas etc. Mas acredito que, se houver respeito e compreensão de ambos, a relação fica ótima.

- $\quad$ É uma relação estável, nem tão amigável, nem distante. Todos se põem em seu lugar, aluno é aluno, professor é professor. Às vezes, há brincadeira para descontrair o ambiente, mas com respeito.

- Regular. Alguns professores não são muito sociáveis.

- A relação é considerada alternada. Exemplo: um dia o professor está tranquilo, mas tem dia que o professor está insuportável e não tem condição nenhuma de ter aula.

- Bom, apesar de que muitos alunos não têm muito respeito com o professor.

- O aluno, apesar das divergências, respeita os professores, pois o nosso futuro está nas mãos deles, e os professores têm que respeitar os alunos também, e ter consciência e preocupação com o que eles irão nos ensinar.

- Ruim, muitas vezes os alunos não respeitam o professor e acabam estragando a aula que o professor prepara durante semanas.

- Algumas boas e outras ruins, depende muito do professor.

- Com a maioria dos professores é boa, a matéria é dada com clareza, e com a maioria há algumas intrigas. Mas nada que tenha me prejudicado.

- De modo geral, tem muitos alunos que não respeitam os professores e vice-versa. Alunos que vêm para a 
escola porque os pais obrigam, ou por outro motivo, mas também tem alunos que têm uma relação agradável com o professor.

- É bastante complicada, pois alguns alunos não se relacionam muito bem com os professores, pois, às vezes, e somente às vezes, eles discutem de maneira civilizada. Mas fora isso, é bom o convívio de ambos os lados.

- De maneira generalizada os alunos possuem uma relação bastante complicada com os professores, pois nem sempre há a presença de respeito.

- Não é amistosa, ainda mantêm aquele pensamento de que o professor é acima do bem e do mal, não há interação. ${ }^{6}$

Dos relatos dos alunos, pode-se identificar a complexidade e a dinâmica das relações entre alunos e professores. Apesar de dizerem ter boa relação, há registros de desrespeitos, tensões e conflitos.

Na identificação da relação com os colegas sobre os aspectos de cordialidade e de amizade, as respostas se centraram nas seguintes afirmações:

- Não, estamos em uma sociedade de falsos; todos se tratam bem, mas no fundo são hipócritas.

- $\quad$ Sim. Pois os alunos se relacionam melhor entre eles do que com os professores.

- Sim, eu converso com todos da sala, respeito eles para que eles me respeitem também. Dou-me muito bem com todos.

- Sim, me relaciono bem com os outros alunos, até com os que não conversam muito, tento manter uma boa relação com todos.

- Com certeza sou extremamente tolerante e preciso ser justa com os meus amigos.

- Sim, mas com algumas pessoas não tenho muita afinidade.

- Sem dúvida, meus colegas fazem suas brincadeiras sem faltar com respeito, mantendo assim um nível cordial e amigável no ambiente escolar.

- Sim, sou amigável com todos.

- Sim, afinal temos que conviver com eles durante um ano. Convivo com meus amigos, às vezes, até mais que com minha família.

\footnotetext{
${ }^{6}$ Respostas da pesquisa realizada com os alunos.
} 
- $\quad$-Sim, acho que todos nós temos diferenças, mas sabemos conviver em grupo.

- Acho que sim porque, quando tem amizade, a turma é unida, então não fica desunida, com aquele grupinho separado.

- Muito bom. Todos se ajudam e não há muitas brigas quanto de costume dos outros anos.

- Também é alternada.

- Sim, é amigável; há uma boa interação.

- Sim, converso com todos; não concordo com alguns colegas nos seus pontos de vista, mas também não arrumo briga com eles, respeito a todos assim com quero ser respeitada.

- Sim eu procuro me dar bem com todos.

\subsection{Relação Aluno/Escola}

Para a pergunta: Qual a importância da escola para você? É um lugar para estudo e/ou convivência? As respostas foram as seguintes:

- $\quad$ Para mim, é uma união entre as duas características; é o local onde eu passo a maior parte do meu tempo, portanto, sempre adquiro amigos, e estou na escola para ampliar meus conhecimentos para ocupar um lugar na sociedade.

- Ambos são muito importantes. Na escola aprendemos como participar da sociedade. E, para isso, é preciso se relacionar com os colegas e aprender.

- De certa maneira são ambos, porque a escola é um lugar para se estudar, aprender, ensinar e, fazendo isso, de certa maneira, já está acontecendo um relacionamento.

- Ambos, pois cada ser humano vive de aprendizado e também convive muito bem com as outras pessoas. Necessito muito de aprendizagem e para isso preciso da escola.

- A escola é muito importante, ela está na fase em que o homem mais precisa de interação social. É um lugar de estudo e convivência.

- A escola é importante para não ficar 'vadiando' nas ruas; é um lugar para estudar. 
- A escola, sem dúvida, é o lugar para praticar o estudo, porém não deixa de ser um ambiente de convivência; afinal, é na escola que passamos a maior parte do nosso tempo.

- Os dois, pois na escola você conhece pessoas e ao mesmo tempo estuda.

- Os dois, é claro; e os dois são importantes tanto para a vida pessoal como profissional no futuro.

- Em minha opinião, escola é lugar para os dois, pois o aluno vem para o colégio aprender, crescer e ser alguém na vida, com futuro promissor, e aprender a viver socialmente, se adaptar com culturas e personalidades diferentes.

- A escola é muito importante, pois nela os alunos têm mais disciplina e aprendem as coisas da vida.

- A escola tem como finalidade formar adultos prontos para a sociedade, por isso, faz parte tanto do aprendizado quanto da convivência.

- Os dois, porque tem seu momento de convivência com os amigos e também temos a hora de estudar.

- É um lugar de estudo e convivência porque a cada fase que passamos, criamos amizades através da convivência.

- É muito importante, pois aprendo ser uma cidadã, conhecer os meus direitos e deveres, conviver com as pessoas totalmente diferentes uma das outras, descobrir o que eu quero para o meu futuro no mercado de trabalho etc, ou seja, é na escola que aprendo a ter um convívio social.

- Sim, é um lugar onde você se relaciona com as pessoas em busca de um conhecimento básico que você leva para a vida toda. ${ }^{7}$

Os dados e as informações permitiram identificar que a escola, objeto desta pesquisa, apresenta várias dimensões pelas quais se podem observar indícios de conflitos e indícios de violência, mesmo que seja na forma indireta simbólica. No entanto, pode-se inferir que a relação entre alunos é razoável, pois alegam que a escola, além de ser importante para estudar, é importante para socialização e para que mantenha vínculos de amizade com os colegas da classe. Quando um aluno interage com outros, torna-se mais fácil o aprendizado. Para os alunos, há professores que têm uma boa relação, mas há outros com os quais a relação não é

\footnotetext{
7 Respostas da pesquisa realizada com os alunos.
} 
amigável, pois em vez de conquistar o respeito dos alunos, impõem aos alunos o respeito, tornando a relação desagradável, rigorosa e autoritária.

\subsection{Relação professor/aluno e relação professor/professor}

Alguns fatores contribuem para a qualidade das relações entre alunos e professores. O desempenho pedagógico dos professores pode influenciar na avaliação dos alunos, assim como a relação pedagógica em sala de aula e a forma de ensinar e de avaliar.

Para identificar a visão dos professores acerca da relação aluno/professor, foi realizada uma entrevista, tendo como base a pergunta: Em sua opinião, como é a relação entre alunos e professores?

As respostas centraram-se nos seguintes pontos:

- Eu considero os alunos daqui tranquilos no que diz respeito ao tratamento com os professores. Não vejo episódios de agressão física ou mesmo verbal (raramente acontece).

- Eu, particularmente, tenho um relacionamento baseado no respeito e na educação com meus alunos e até mesmo no carinho.

- Ótima! Os alunos são bem receptivos, educados, isso, digo por mim, pelo que vejo e percebo.

- Ótima, mas os alunos não demonstram interesse nas propostas pedagógicas, e isso desestimula um pouco.

- Boa. Os alunos da escola apresentam 'problemas de comportamento normais' para sua faixa etária; em geral, são carinhosos, afetuosos e respeitosos. Gosto muito deles.

- Joia, porque o pessoal é muito legal. Participativos quando querem.

- De um modo geral, a convivência é tranquila. Afirmo isso, porque algumas colegas reclamam da falta de compostura de alguns alunos para com elas. 
Para a pergunta: Em sua opinião, como é a relação professor/professor?, as respostas foram as seguintes:

- Nem tudo pode ser perfeito e essa situação encaixa-se. Convivência normal.

- Joia! Todo mundo está a fim de trabalho.

- Conflituosa. A principal dificuldade e motivo de conflito é o não cumprimento do que fica estabelecido em coordenação, por exemplo: datas para entrega das questões para elaboração da prova interdisciplinar.

- Da minha parte, nada tenho a dizer sobre esse relacionamento, pois cheguei a esta escola este ano. Mas, a meu ver, são ótimas pessoas.

- Boa, poderia ser melhor, poderíamos caminhar juntos em todos os sentidos, nas decisões etc.

- Há divergências de opiniões. É difícil conseguir um consenso, às vezes, em questões simples; no entanto, eu tenho boas relações com todos. ${ }^{8}$

$\mathrm{Na}$ escola pesquisada, a relação entre professores e alunos mantém-se harmoniosa na medida do possível. Os professores alegam que, embora haja conflitos entre professores e coordenação em relação a assuntos diversos, tais como datas e questões disciplinares, existe boa relação de maneira geral. Muitos professores entrevistados chegaram há pouco tempo no colégio, não se considerando, portanto, aptos a responder a respeito disso no momento. Porém, dizem que pelo pouco que viram, percebem entusiasmos com o trabalho realizado na escola.

\subsection{Relação aluno/funcionário e relação funcionário/funcionário}

O relacionamento entre alunos e funcionários é muito importante, pois há convivência estreita entre eles. $\mathrm{O}$ trabalho do funcionário está relacionado com a supervisão do espaço escolar e implica, portanto, contato com os alunos. Na maioria das vezes, funcionários têm a obrigação de fazer valer regras que os estudantes não acatam, gerando conflitos. Quando há desentendimentos em torno das normas escolares, alguns alunos, muitas vezes, passam a ter atitudes de rebeldia.

\footnotetext{
8 Perguntas e respostas da pesquisa realizada aos professores.
} 
A falta de funcionários para auxiliar na organização dos espaços e do controle dos alunos pode ser caracterizada como impacto negativo para a relação, pois são poucos para controlar um grande número de estudantes. Outro problema para ser destacado é a falta de preparo dos funcionários para lidar com os alunos. No entanto, não se deve deixar de mencionar que é possível encontrar funcionários que são próximos e amigos.

Para identificar o que pensam os funcionários da relação aluno/funcionário foram realizadas entrevistas, tendo como suporte a seguinte pergunta: Em sua opinião, como é a relação dos alunos com os funcionários?

- Boa, mas precisa ser melhorada.

- Um pouco complexo, às vezes existem os problemas do dia a dia. Mas, resumidamente.

- Particularmente, os alunos são bons. Alguns têm seus problemas, mas nada que não possa se resolver.

- Os alunos, no meu ponto de vista, são ótimos, não tenho nenhum problema. Gosto de todos, são carinhosos.

- Eu observo que a maioria dos alunos, não respeita a categoria. Falta consciência e respeito com as atividades exercidas pela categoria.

E entre os funcionários?

- Eu me relaciono muito bem com meus colegas de trabalho.

- Acredito que problemas do dia a dia existem, mas acho que os funcionários têm um bom relacionamento entre si.

- Tumultuada e estressante. Existem muitos conflitos dentro da categoria.

- Ótima, tenho amizade com todos meus colegas de trabalho.

- Eu me relaciono muito bem com professores, alguns colegas são bons, e entre outros é difícil a comunicação. ${ }^{9}$

\footnotetext{
9 Perguntas e respostas da pesquisa realizada aos funcionários.
} 
A maioria dos funcionários do colégio diz estar satisfeita com o tratamento dado pelos alunos. Com exceção de alguns alunos, grande parte respeita o trabalho da categoria.

\subsection{Relação aluno/diretor}

O relacionamento aluno-diretor, às vezes, pode ser bem problemático, pois é uma relação distanciada e ausente, com pouco diálogo. Não são todos os diretores que mantêm bom relacionamento com os alunos.

É comum a referência ao autoritarismo, a abusos de poder por parte de diretores e à falta de abertura para a participação dos alunos. O diretor é reconhecido como autoridade da escola e como o responsável por fazer valer as regras e as normas, de modo que a escola funcione adequadamente.

Ao ser questionado, o diretor identificou a sua relação com os alunos da escola como satisfatória. Afirmou também que o ambiente de trabalho com os estudantes é tranquilo e, de maneira geral, é produtivo.

O diretor considerou em sua entrevista a relação com os professores e funcionários como sendo democrática e participativa. Fez questão de pôr em evidência o seu profissionalismo, ainda que haja turbulências.

\section{Considerações finais}

Após a realização da pesquisa, pode-se concluir que conflitos e algumas formas de violências se manifestam na escola como, por exemplo, a violência intersegmentada e até mesmo a violência intrasegmentada. Identificam-se as seguintes atitudes consideradas como conflituosas e violentas, vivenciadas dentro do colégio, a partir de observações e registro de entrevistas: 
- Agressões verbais como palavras de baixo calão, gritos, xingamentos e ofensas diversas.

- Desrespeito ao próximo, como empurrar pessoas ao andar pelos corredores e esbarrar propositadamente com o fim de bater em alguém que esteja vindo.

- Preconceito em relação à classe social, à hierarquia ocupada dentro da instituição e ao local de moradia.

- Desrespeito ao patrimônio público, observado pelas pichações, roubo de material de estudo, depredação do ambiente e lixo jogado no chão.

- Em casos extremos, até agressões físicas e brigas acarretadas por motivos torpes, como uma ofensa ou divergência de opinião.

- Agressões de alunos contra professores.

A escola reflete contradições e discursos ambíguos. Mas, por outro lado, existe um cotidiano que é real no qual a práxis do professor tem o seu campo transformador. Essas questões apontam para a necessidade de se trabalhar a cultura da paz, os valores, os princípios de solidariedade, de tolerância e de respeito às diferenças. A escola, ao identificar indícios de violência, deve desenvolver ações pedagógicas permanentes e constantes para uma educação cidadã e emancipatória.

\section{School,conflict and violence}

\section{Abstract}

This research aimed to study the violence and social relations at school, in order to identify the manifestations of violence either real or perceived, direct or indirect. The main focus was to examine the reality of a public school in the Federal District. The methods were used as reference data and observations collected through interviews and direct observation in the school routine. The results indicate that violence permeates and are present in social relations and educational school, revealed by teachers, students and staff.

Keywords: School. Social relations. Violence. 
80 Univ. Hum., Brasília, v. 7, n. 1/2, p. 55-80, jan./dez. 2010
Dirce M. da Fonseca, Filipe F. Marques, Philippe Vitoriano, Emily M. Xavier

\section{Referências}

ABRAMOVAY, Miriam. Escola e violência. Brasília: UNESCO, UCB, 2003.

ABRAMOVAY, Miriam; RUA, Maria das Graças. A violência nas escolas. Brasília: UNESCO, 2002.

BOTTOMORE, T. Dicionário do pensamento marxista. Rio de Janeiro: J. Zahar, 1988.

SPOSITO, Marilia Pontes. A instituição escolar e a violência. Cadernos de Pesquisa da Fundação Carlos Chagas, São Paulo, n. 1, 2001. 